\title{
IMPROVED TUBE CRACKER FOR OPENING VACUUM-SEALED GLASS TUBES
}

\author{
Glenn A Norton \\ Center for Sustainable Environmental Technologies, Iowa State University, 276 Metals Development Building, Ames, \\ Iowa 50011, USA. Email: norton@ameslab.gov.
}

\begin{abstract}
A variety of analytical procedures involve breaking open a glass or quartz vessel containing a gaseous sample, and then quantitatively collecting the sample gases for analysis. In order to do this, a variety of "tube crackers" have been used. This paper discusses an alternate tube cracker that offers numerous advantages over those that have been discussed previously in the literature.
\end{abstract}

\section{PREVIOUS TECHNIQUES}

In one previous approach, a tube cracker is used to break pieces of standard quartz or glass tubing which has been sealed on both ends and contains the sample gases of interest (DesMarais and Hayes 1976). This was offered as a preferred alternative to conventional glass breakseals. The tube cracker uses standard Cajon Ultra Torr ${ }^{\mathrm{TM}}$ fittings, along with commercially available corrugated, flexible stainless steel tubing. In that approach, the sample tube is scored, inserted into the tube cracker, and then broken (where the tube was scored) by bending the corrugated steel tubing. It is necessary to fabricate 2 steel cones that serve as liners, which are inserted into the Ultra Torr fittings. The scoring on the tube needs to be situated so it is in between the tips of the 2 steel cones, which ensures that the break occurs in the intended location. We have successfully used this type of tube cracker in our laboratories; however, a number of disadvantages to that approach were noted. For example, difficulties were encountered in positioning the sample tube at the precise location needed for a clean break. This was largely due to the fact that it was impossible to view the tube inside the tube cracker, since it was positioned inside the corrugated steel tubing. The matter is made even worse by the fact that the length of the corrugated tubing can change after bending it a number of times. It can always be collapsed back to its original length, but maintaining a constant length is very difficult due to the corrugated nature of the tubing. Because the length of the corrugated tubing is not constant, this complicates correct positioning of the sample tube in the tube cracker. We view the "blind" cracking of the sample tube as being a major disadvantage of this approach. Other researchers have also reported that the correct positioning of the tubing inside the cracker is difficult because the tubing cannot be seen (Kennedy and Kennedy 1994). In that work, the authors also note that the large surface area of the corrugated tubing can extend the retention time of the gases inside the tube cracker. In addition, glass shards can be trapped between the corrugations in the flexible tubing, which can eventually lead to leaks in the tubing.

In an alternate tube-cracking approach, a sealed sample tube (which tapers to a point on one end) is placed inside a Pyrex ${ }^{\mathrm{TM}}$ tube that is closed at the bottom (Kennedy and Kennedy 1994). The Pyrex tube has the barrel of a stopcock sealed into the side wall (located on the upper third of the tube). The sample tube is broken by closing the tap onto the tapered end of the sealed sample tube. A possible drawback to this method is that the fine, tapered tips on the sample tubes are extremely fragile. This increases the chances of accidental breakage and loss of the sample. This is of particular concern in applications where a sample is sealed within a quartz vessel and then combusted at high temperatures, which can result in considerable pressures inside the sample vessel.

Other researchers have also reported the use of a stopcock-type design for breaking sample tubes housed in a glass holder. In one paper, the barrel of a greaseless stopcock was mounted into the wall of the tubing on a standard ball joint, which was closed on the end opposite of the ball joint (Caldwell et al. 1983). Sample tubes are broken by turning the threaded cap on the stopcock and driving the piston in the stopcock against the sample tube. 
In yet another study, a greased ball joint was used to break glass tubes (Coleman 1981). The socket end of the ball joint had an adapter on the opposite end to accept glass tubes of the desired diameter. The scored glass tube to be broken is then slid into the adapter and through the ball and socket junction of the greased ball joint. The tube is subsequently broken by slightly flexing the adapter (which has the socket portion of the ball joint) that connects to the ball portion of the joint.

\section{THE IMPROVED TECHNIQUE}

In our work, we routinely use a tube cracker similar to that reported by DesMarais and Hayes (DesMarais and Hayes 1976). However, a number of modifications were made to greatly improve performance and ease of use. In our design, the corrugated steel tubing is replaced by a 6 " length of smooth $3 / 8^{\prime \prime}$ OD $\times 5 / 16^{\prime \prime} \mathrm{ID}(9.6 \mathrm{~mm} \times 8.0 \mathrm{~mm})$ PFA tubing having a 1/32" $(0.8 \mathrm{~mm})$ wall. The $6 "$ length provides more than adequate tubing flexibility for the break to be easily made. One end of the PFA tubing is connected to a manifold by using a standard Swagelok ${ }^{\mathrm{TM}}$ fitting. The other end of the tubing is fitted with a Cajun Ultra Torr $3 / 8^{\prime \prime} \times 1 / 4^{\prime \prime}$ reducing union that has been bored through to enable $1 / 4^{\prime \prime}$ glass tubing to slide all the way through the fitting. Quartz sample bulbs that have $1 / 4^{\prime \prime}$ OD stems at the top are used whereby the $1 / 4^{\prime \prime}$ OD quartz tubing is scored and inserted into the Ultra Torr fitting at the bottom of the tube breaker until the scoring on the tube is in the center 2 " of the PFA tubing. Depending on the application, the diameter of the quartz or glass tubing can be increased after making appropriate modifications to the tube cracker (provided that suitable fittings are available for that size of tubing). Because there is a lot of leeway on how far the $1 / 4$ " glass tubing slides into the PFA tubing, the operator has a great deal of flexibility regarding the length of the tube to be broken and where the break occurs along the length of that tube.

While using this simplified tube cracker in our laboratories, it has performed easily and flawlessly. In addition, it has exhibited superior performance relative to the tube cracker that employs the flexible corrugated steel tubing. Unlike the latter approach, our method uses only commercially available components (i.e. no steel cones need to be manufactured). Since the tubing is translucent, the operator can see everything in the tube cracker, including the exact location and orientation of the scoring. This facilitates making clean breaks and is one of the major advantages of our approach. In addition, because the operator can see everything in the tube breaker, the insertion depth of the glass tube into the tube breaker does not have to be precisely measured and controlled (as it does with the corrugated steel tubing) in order to get a clean break. Unlike some of the other tube crackers, our design does not contain any fragile (e.g. glass housings) or greased components. Because the tubing is smooth rather than corrugated, it is easy to clean (although it is probably best to simply replace the tubing since a new piece costs less than \$2), and there are no "pockets" where shards of glass can accumulate. For most applications, this type of tube breaker should be considered as an alternative to other types of tube crackers discussed in the literature.

\section{ACKNOWLEDGMENTS}

This work was supported by the US Department of Agriculture's Office of Energy Policy and New Uses through a cooperative agreement with Iowa State University.

\section{REFERENCES}

Caldwell WE, Odom JD, Williams DF. 1983. Glass-sample-tube breaker. Analytical Chemistry 55:1175-6.

Coleman DD. 1981. Tube cracker for opening samples sealed in glass tubing. Analytical Chemistry 53:19635 .

DesMarais DJ, Hayes JM. 1976. Tube cracker for open- ing glass-sealed ampoules under vacuum. Analytical Chemistry 48(11):1651-2.

Kennedy H, Kennedy DP. 1994. Simplified tube cracker for opening samples sealed in glass tubes while under vacuum. Analytical Proceedings Including Analytical Communications 31:299-300. 